\section{Pattern of morbidity among elders attending general practice: health needs assessment of geriatric patients in Oman}

\author{
Shaikh Muhammad Naeem, ${ }^{1}$ \\ Firdous Jahan, ${ }^{1}$ \\ Muhammad Asadullah Siddiqui, ${ }^{2}$ \\ Muhammad Moazzam Khan ${ }^{1}$ \\ ${ }^{1}$ Department of Family Medicine, \\ Oman Medical College, Oman; \\ ${ }^{2}$ Saskatchewan Health Authority, \\ Regina, SK, Canada
}

\section{Abstract}

The main purpose of this study was to identify specific problems and pattern of morbidities that is common in the elderly. A cross sectional study surveying the health status and needs of targeted population was conducted in selected primary health care (PHC) outpatient settings. All consenting individuals aged 60 years and above who visited the selected PHC clinics were interviewed. Information was collected using face-to-face interviews based on a structured, pre-tested questionnaire. A total of 185 people were evaluated in this study. About $75 \%$ of participants were age 60-70 years. Overall, male predominance was noted with 137 (74.1\%) males and among all participant's $80 \%$ were married. The mean BMI was $26.47 \pm 4.98 \mathrm{~kg} / \mathrm{m}^{2}$ and mean waist circumference was $90.16 \pm 12.97 \mathrm{~cm}$. The prevalence of smoking, DM, HTN, dyslipidaemia and history of IHD among participants were $7.6 \%, 37.8 \%, 49.7 \%, 27.6 \%$ and $8.1 \%$, respectively and males showed a significantly higher prevalence than females in smoking and HTN $(p<0.05)$. Hypertension was common comorbid ailment with $29.2 \%$ of stage I and $19.5 \%$ of stage II hypertension among 60-70 age groups. The majority of the participants were taking shower; using toilet, feeding and get dressed independently, $88.6 \%$, $87.6 \%, 87 \%$ and $87.6 \%$ respectively. These findings provide important information on high prevalence of overweight, hypertension, diabetes, smoking and dyslipidaemia among elders. The other common morbidities were impaired vision, walking difficulty, and hearing problems. The activity of daily living (bathing dressing toileting feeding) is preserved in most of older people.

\section{Introduction}

Elderly population is in a rapid expansion worldwide, as a result of dramatic advances in medicine towards prevention, controlling and curing of diseases that are associated with high mortality. By the year 2025 , people in this age group will reach a total of 1.2 billion and this will rise to 2 billion in year 2050 with $80 \%$ of them living in developing countries. ${ }^{1}$ The sultanate of Oman is no exception of this global trend, especially with the dramatic increase in life expectancy for Omani people over the last four decades. Elderly in Oman constituted $3 \%$ of the population in 1993 , increased to $3.5 \%$ in 2010 and is expected to reach $15.2 \%$ by $2050 .^{2}$ Oman has generally triumphed over the epidemic of communicable and deficiency diseases (characteristics of underdevelopment) $)^{3-5}$ and crossed the transition phase towards the epidemic of chronic non-communicable and affluence diseases (characteristic modernization and advanced levels of development). ${ }^{6}$

Primary Health Care (PHC) physicians, managing the geriatric care clinic, usually initiates a comprehensive assessment of older clients attending the clinic. ${ }^{7}$ Each clinic has a catchment area, and older individuals in that area are usually being called, at least initially, for such assessment. Like an effective medical evaluation, the geriatric assessment needs to be sufficiently flexible and adaptable. Effective primary care management of geriatric health issues, with its goal of caring for healthy and functional elderly patients, may perhaps be better described as a comprehensive health screening. ${ }^{8}$ Disease management not only need professional skills but also requires family support as well as social rehabilitation facilities in order to allow older individuals being effective members of community at their late life. ${ }^{9-11}$

According to United Nation and World Health Organisation estimations, the population in the elderly age group is growing in the Sultanate due to the impressive health, social and economic development is estimated to go up to $10 \%$ of the total population by the year 2025. Ministry of health integrated the elderly care in the band of primary health care services in the new seventh fifth year plan for ministry of health through the plan of primary health care domain, which aims to reduce morbidity in elderly age group and early detection of old age diseases and their complications. ${ }^{12}$ In view of vulnerability of older people and their growing number in Oman, a study was conducted in South Batinah Governorate to identify specific problems and pattern of morbidities among elders.
Correspondence: Muhammad A. Siddiqui, Department of Research, Saskatchewan Health Authority, Regina, SK, Canada. E-mail: drasadi@hotmail.com

Key words: Elderly; chronic morbidity; activity of daily living; Oman.

Contributions: SMN, conceived the study and collected the data; MAS, analysed and report study data; SMN, MAS drafted the manuscript while FJ and MMK revised and reviewed the whole manuscript. All authors read and approved the final manuscript.

Conflict of interests: the authors declare no conflict of interests.

Received for publication: 15 August 2018 Revision received: 25 October 2018.

Accepted for publication: 16 November 2018.

This work is licensed under a Creative Commons Attribution-NonCommercial 4.0 International License (CC BY-NC 4.0).

(C) Copyright S.M. Naeem et al., 2018

Licensee PAGEPress, Italy

Geriatric Care 2018; 4:7774

doi:10.4081/gc.2018.7774

\section{Materials and Methods}

A cross sectional study surveying the health status and needs of targeted population was conducted in selected PHC outpatient settings in the South Batinah Governorate of Oman. The study was approved by the institutional review board and Ministry of Health, Oman. A structured questionnaire was designed incorporating important barriers and attitudes in research that were identified through an extensive literature search of the Pub Med database. After consensus of all study investigators, we also included some questions, which were particularly important to our local scenario. Questions about past research involvement and experiences were also included. The time required to complete the questionnaire was about 10 to 12 minutes.

\section{Ethics approval and consent to participate}

The study protocol was approved by the Institutional Review Board and Ministry of Health, Oman.

\section{Study participants}

Elderly Omani individuals residing in South Batinah governorate were recruited. A written informed consent was obtained. All consenting individuals aged 60 years and above who visit the selected PHC clin- 
ics were interviewed. Information was collected using face-to-face interviews based on a structured, pre-tested questionnaire. Those who did not give consent and those unable to participate due to their illness were excluded from the study.

The sample size was determined using a single population proportion sample size estimation method by assuming that $50 \%$ of the patients have co morbidities (to obtain the maximum representative sample size since no similar study was found in the region) with 95\% confidence interval and at confidence interval 5. Finally, we calculated 384 patients by using population correction formula.

\section{Data collection}

Data was collected through individual face-to-face interview by trained interviewers using a structured, pre-tested questionnaire. Survey instrument was made after literature search reviewed by and agreed on via several brain storming sessions. The questionnaire thoroughly discussed among the interviewers before data collection to decrease interview bias. Face and content validity of the questionnaire was obtained through a review process with experts in the field. After incorporating the identified inconsistencies and inaccuracies, the questionnaire was piloted.

\section{Statistical analysis}

Study data was analyzed using Statistical Package for Social Sciences (SPSS) version 20 for percentage, frequency and mean. Descriptive statistics used to describe patient's demographics. Chi-square test was used as a test of significance to compare differences between groups for categorical data and using the Mann Whitney U test, a nonparametric statistical test for continuous data.

\section{Results}

A total of 185 people were evaluated in this study. About $75 \%$ of participants were age $60-70$ years, $16.8 \%$ were $70-80$ years and $8.1 \%$ were above 80 years of age. Overall, male predominance was noted with $137(74.1 \%)$ males and among all participant's $80 \%$ were married. The mean BMI was $26.47 \pm 4.98 \mathrm{~kg} / \mathrm{m}^{2}$ and BMI in the males was statistically significantly lower than the females $(\mathrm{P}=0.005)$. Mean waist circumference was $90.16 \pm 12.97 \mathrm{~cm}$ and waist circumference in the male and females did not show any statistical difference $(\mathrm{p}=0.09)$. The prevalence of smoking, DM, HTN, dyslipidaemia and history of IHD among participants were $7.6 \%, 37.8 \%, 49.7 \%$, $27.6 \%$ and $8.1 \%$, respectively and males showed a significantly higher prevalence than females in smoking and HTN $(\mathrm{p}<0.05)$ (Table 1).

The proportion of this cohort that were age 60-70 ( $\mathrm{n}=139)$, hypertension was common comorbid ailment with $29.2 \%$ of stage I and $19.5 \%$ of stage II hypertension affected overall, with the frequency decreasing with increasing age (Table 2). The next most common comorbid ailments were impaired vision $32.4 \%$, walking difficulty $(23.8 \%)$, impaired gait $(18.9 \%)$, impaired hearing (14.6\%), and urinary incontinence (11.9\%).

Participants' were asked multiple questions regarding their daily living activities. Their answers were labelled as independent, with help and dependent (Table 3). Nearly two third $(77.3 \%)$ were not utilising walking aid. The majority of the participants were taking shower; using toilet, feeding and get dressed independently, $88.6 \%$, $87.6 \%, 87 \%$ and $87.6 \%$ respectively. More than a half of the participant's perform their daily activities such as driving, cooking, housekeeping, grocery and self-medication independently.

\section{Discussion}

This study provides the evidence about the prevalence of chronic diseases as well as functional capacity (limitation) in elderly population in Oman. Overall, we found that the functional capacity of elders is not diminished as the age advances but the proportion of chronic diseases is high among this age group. Amongst other included chronic diseases in this study, hypertension was the most common disorder $(50 \%)$ in elderly individuals. ${ }^{13}$ Similar numbers were observed in previous studies carried out in other countries such as in Saudi Arabia (46.5\%) and $67 \%$ in UAE. ${ }^{14,15}$ Moreover, another study conducted in Fayoum rural district in Egypt reported 37.4\% hypertensive elders. ${ }^{16}$ The increasing prevalence of hypertension within elder population may be attributed to change in living standard in the past many years. However, the prevalence of hypertension is still considerably lower than other European countries such as in France $(67 \%)$, Italy $(71 \%)$ and in England $(81 \%) .{ }^{17,18}$ On the other hand, few studies show lower proportion of elders has hypertension such as in Korea (9.2\%) and in Vietnam $(15 \%) .{ }^{19,20}$

Two out of five individuals $(37.8 \%)$ in this study, reported diabetes which was similar with Saudia (36.5\%), 52\% UAE. ${ }^{14,21}$ However, other countries data shows lower prevalence such as Albania (19\%), Germany (17\%), and in China 24.8\%.22-24 Danaei et $a l .^{25}$ had reported that diabetes was rising globally, driven by both population growth and ageing with increasing age-specific prevalence. In contrast, prevalence of diabetes was quite low in Thailand (14.8\%), Korea (2.8\%) and Vietnam $<1 \% .^{19,20,26}$ Dyslipidaemia is one of the four proven conventional risk factors for coronary heart diseases besides cigarettes smoking, diabetes, and hypertension. ${ }^{27}$ Our study showed almost one third of the participant (27\%) had high lipids. Previous studies performed in Saudi Arabia found 52.9\%, and in UAE $28.6 \%$ prevalence. ${ }^{14,28}$ In a survey conducted in the town of Sarih in north of Jordan, 59\% of people aged $\geq 60$ year has dyslipidaemia. ${ }^{29}$

Table 1. Frequencies of study participants' risk factors.

\begin{tabular}{lcc} 
Variables & Frequencies & Percentages \\
Smoking & & \\
Yes & 14 & 7.6 \\
No & 164 & 88.6 \\
Ex-smokers & 7 & 3.8 \\
DM & & \\
Yes & 70 & 37.8 \\
No & 115 & 62.2 \\
\hline HTN & & \\
Yes & 92 & 49.7 \\
No & 93 & 50.3 \\
Dyslipidaemia & & \\
Yes & 51 & 27.6 \\
No & 134 & 72.4 \\
\hline IHD & & \\
Yes & 15 & 8.1 \\
No & 170 & 91.9 \\
COPD & & \\
Yes & 9 & 4.9 \\
No & 176 & 95.1 \\
\hline
\end{tabular}

\section{Arthritis}

\begin{tabular}{lcc} 
Yes & 28 & 15.1 \\
No & 157 & 84.9 \\
Low backache & & \\
Yes & 7 & 3.8 \\
No & 178 & 96.2 \\
\hline
\end{tabular}

\section{Stroke}

$\begin{array}{lcc}\text { Yes } & 9 & 4.9 \\ \text { No } & 176 & 95.1\end{array}$

$\begin{array}{lll}\text { No } & 176 & 95.1\end{array}$

\begin{tabular}{lcc} 
Renal disease & & \\
Yes & 2 & 1.1 \\
No & 183 & 98.9 \\
\hline
\end{tabular}

Cancer

$\begin{array}{lcc}\text { Yes } & 1 & 0.5 \\ \text { No } & 184 & 99.5\end{array}$

\begin{tabular}{lcc} 
Psychiatric issues & & \\
Yes & 2 & 1.1 \\
No & 183 & 98.9 \\
\hline
\end{tabular}

\section{Skin problems}

\begin{tabular}{lcc} 
Yes & 3 & 1.6 \\
No & 182 & 98.4 \\
\hline
\end{tabular}


Another study conducted in Wrdha district, India reported $40 \%$ elders have high lipids. ${ }^{30}$

The present study findings showed that the prevalence of current smoking in elders in Oman is $7.6 \%$ that was lower than the Saudi Arabia 25\% and Lebanon (25\%). ${ }^{31,32}$ In a cross sectional survey conducted in a random general population of eleven countries such as Algeria, Egypt, Jordan, Morocco, Pakistan, Saudi, Syria, Tunisia, Turkey, and UAE. $29.8 \%$ elders are smokers. ${ }^{33}$ In Europe $11.5 \%$ elders are smokers, a similar prevalence was observed among older adults among the elders in Canada (12\%). ${ }^{34,35}$ In 2010, Ischemic heart disease was the leading cause of mortality worldwide. ${ }^{36}$ Projections reveal that ischemic heart disease mortality in the Middle East countries will increase at a rate compared to other regions. ${ }^{37}$ The result of the current study showed that $15 \%$ Omani older adults have IHD, this is closer to elders in Saudi $16.7 \%, 15 \%$ in UAE, and $14 \%$ in Lebanon. . $^{14,38,39}$

The prevalence of osteoarthritis was estimated to be $15 \%$ in the present study. The prevalence was lower than UAE where it was $45 \%$ in elders. ${ }^{14}$ Other studies conducted in Southern region of Saudi where it is $24 \%$, and in Egypt it was $42 \% .^{38,39}$ Obesity is a risk factor for coronary heart diseases, and it is strongly associated with diabetes and hypertension and impaired quality of life. ${ }^{40}$ Omani elders have high prevalence of overweight/obesity $\left(\mathrm{BMI} \geq 25 \mathrm{~kg} / \mathrm{m}^{2}\right) 77 \%$ Omani elders are overweight this is similar to Saudi $71 \%$, Egyptians $(65 \%)$ and to Lebanon $68 \% .^{16,32,41}$ In another study conducted in north of Jordan reported $90 \%$ of overweight/obesity in elder population. ${ }^{42}$

Functional limitations was investigated through activities of daily living (ADL), a five item scale commonly used in comprehensive geriatric assessment evaluating the basic activates such as bathing, toileting, clothing, walking and eating by his/her own, $87 \%$ of elders can perform bathing, toileting, feeding and dressing independently while $77 \%$ can walk independently, this data similar to another assessment in Oman where $75 \%$ elders are independent to perform ADL, ${ }^{43}$ in Saudi Arabia Qassim region almost $90 \%$ elders can perform these four activities independently ${ }^{44}$ in another cross sectional study in Lebanon where $76 \%$ of participant can perform basic ADL independently. ${ }^{32}$ In Jordan, more than $80 \%$ older

Table 2. Distribution of geriatric morbidity.

\begin{tabular}{|c|c|c|c|c|c|}
\hline Variable & Total $(n=185)$ & $60-70(n=139)$ & $70-80(n=31)$ & $>80(n=15)$ & P-value \\
\hline $\begin{array}{l}\text { BP } \\
\text { Normal } \\
\text { Pre hypertension } \\
\text { Stage 1 } \\
\text { Stage } 2\end{array}$ & $\begin{array}{l}36(19.5) \\
59(31.9) \\
54(29.2) \\
36(19.5)\end{array}$ & $\begin{array}{l}26(14.1) \\
46(24.9) \\
41(22.2) \\
26(14.1)\end{array}$ & $\begin{array}{c}6(3.2) \\
11(5.9) \\
8(4.3) \\
6(3.2)\end{array}$ & $\begin{array}{l}4(2.2) \\
2(1.1) \\
5(2.7) \\
4(2.2)\end{array}$ & 0.821 \\
\hline $\begin{array}{l}\text { Dementia } \\
\text { Yes } \\
\text { No }\end{array}$ & $\begin{array}{c}15(8.1) \\
170(91.9)\end{array}$ & $\begin{array}{c}6(3.2) \\
133(71.90)\end{array}$ & $\begin{array}{c}4(2.2) \\
27(14.6)\end{array}$ & $\begin{array}{c}5(2.7) \\
10(5.4)\end{array}$ & $<0.001$ \\
\hline $\begin{array}{l}\text { Depression } \\
\text { Yes } \\
\text { No }\end{array}$ & $\begin{array}{c}11(5.9) \\
174(94.1)\end{array}$ & $\begin{array}{c}6(3.2) \\
133(71.9)\end{array}$ & $\begin{array}{c}2(1.1) \\
29(15.7)\end{array}$ & $\begin{array}{c}3(1.6) \\
12(6.5)\end{array}$ & 0.05 \\
\hline $\begin{array}{l}\text { Gait } \\
\text { Impaired } \\
\text { Normal } \\
\end{array}$ & $\begin{array}{c}35(18.9) \\
150(81.1)\end{array}$ & $\begin{array}{c}13(7) \\
126(68.1)\end{array}$ & $\begin{array}{l}14(7.6) \\
17(9.2)\end{array}$ & $\begin{array}{l}8(4.3) \\
7(3.8)\end{array}$ & $<0.001$ \\
\hline $\begin{array}{l}\text { Vision } \\
\text { Impaired } \\
\text { Normal }\end{array}$ & $\begin{array}{c}60(32.4) \\
125(67.6)\end{array}$ & $\begin{array}{c}29(15.7) \\
110(59.5)\end{array}$ & $\begin{array}{c}20(10.8) \\
11(5.9)\end{array}$ & $\begin{array}{c}11(5.9) \\
4(2.2)\end{array}$ & $<0.001$ \\
\hline $\begin{array}{l}\text { Hearing } \\
\text { Impaired } \\
\text { Normal } \\
\end{array}$ & $\begin{array}{c}27(14.6) \\
158(85.4)\end{array}$ & $\begin{array}{l}15(8.1) \\
124(67)\end{array}$ & $\begin{array}{l}7(3.8) \\
24(13)\end{array}$ & $\begin{array}{c}5(2.7) \\
10(5.4)\end{array}$ & 0.024 \\
\hline $\begin{array}{l}\text { Insomnia } \\
\text { Yes } \\
\text { No }\end{array}$ & $\begin{array}{c}20(10.8) \\
165(89.2)\end{array}$ & $\begin{array}{c}10(5.4) \\
129(69.7)\end{array}$ & $\begin{array}{c}6(3.2) \\
25(13.5)\end{array}$ & $\begin{array}{c}4(2.2) \\
11(5.9)\end{array}$ & 0.017 \\
\hline $\begin{array}{l}\text { Body pain } \\
\text { Yes } \\
\text { No }\end{array}$ & $\begin{array}{c}20(10.8) \\
165(89.2)\end{array}$ & $\begin{array}{c}9(4.9) \\
130(70.3)\end{array}$ & $\begin{array}{c}8(4.3) \\
23(12.4)\end{array}$ & $\begin{array}{c}3(1.6) \\
12(6.5)\end{array}$ & 0.004 \\
\hline $\begin{array}{l}\text { Loss of appetite } \\
\text { Yes } \\
\text { No }\end{array}$ & $\begin{array}{c}12(6.5) \\
173(93.5)\end{array}$ & $\begin{array}{c}4(2.2) \\
135(73)\end{array}$ & $\begin{array}{c}4(2.2) \\
27(14.6)\end{array}$ & $\begin{array}{c}4(2.2) \\
11(5.9)\end{array}$ & 0.001 \\
\hline $\begin{array}{l}\text { Urinary incontinence } \\
\text { Yes } \\
\text { No }\end{array}$ & $\begin{array}{c}22(11.9) \\
163(88.1)\end{array}$ & $\begin{array}{c}8(4.3) \\
131(70.8)\end{array}$ & $\begin{array}{c}9(4.9) \\
22(11.9)\end{array}$ & $\begin{array}{c}5(2.7) \\
10(5.4)\end{array}$ & $<0.001$ \\
\hline $\begin{array}{l}\text { Stool incontinence } \\
\text { Yes } \\
\text { No }\end{array}$ & $\begin{array}{c}11(5.9) \\
174(94.1)\end{array}$ & $\begin{array}{c}6(3.2) \\
133(16.2)\end{array}$ & $\begin{array}{c}1(0.5) \\
30(16.2)\end{array}$ & $\begin{array}{c}4(2.2) \\
11(5.9)\end{array}$ & 0.002 \\
\hline $\begin{array}{l}\text { Walking difficulty } \\
\text { Yes } \\
\text { No }\end{array}$ & $\begin{array}{c}44(23.8) \\
141(76.2)\end{array}$ & $\begin{array}{c}22(11.9) \\
117(63.2)\end{array}$ & $\begin{array}{l}14(7.6) \\
17(9.2)\end{array}$ & $\begin{array}{l}8(4.3) \\
7(3.8)\end{array}$ & $<0.001$ \\
\hline
\end{tabular}


people can perform bathing, toileting, feeding and dressing independently. ${ }^{45}$ In India, Ahmedabad, 90\% elders can perform these four activities without help. ${ }^{46}$ Geriatric population in this study have shown a good personal daily activity by their own. The result is very encouraging, however this is imperative to promote and improve the geriatric health in Oman managing common issues and updating physicians regarding evolving problems.

\section{Conclusions}

Geriatric population tends to develop more chronic disease state, develop frailty and dependency, and reduced quality of life. The study results provide important information on high prevalence of overweight, hypertension, diabetes, smoking and dyslipidaemia among elders. The other common morbidities were impaired vision, walking difficulty, and hearing problems. The activity of daily living (bathing dressing toileting feeding) is preserved in most of older people.

\section{References}

1. World Health Organization. Active ageing: a policy framework; 2002. Available from: http://www.who.int/ageing/publi-

Table 3. Difficulties of daily living activities.

\begin{tabular}{|c|c|c|c|c|c|}
\hline & Total $(\mathrm{n}=185)$ & $60-70(n=139)$ & $70-80(n=31)$ & $>80(\mathrm{n}=15)$ & P-value \\
\hline $\begin{array}{l}\text { Walking aid } \\
\text { Yes } \\
\text { No }\end{array}$ & $\begin{array}{c}42(22.7) \\
143(77.3)\end{array}$ & $\begin{array}{c}19(13.7) \\
120(86.3)\end{array}$ & $\begin{array}{l}13(41.9) \\
18(58.1)\end{array}$ & $\begin{array}{c}10(66.7) \\
5(33.3)\end{array}$ & $<0.001$ \\
\hline $\begin{array}{l}\text { Shower } \\
\text { Independent } \\
\text { With help } \\
\text { Dependent }\end{array}$ & $\begin{array}{c}164(88.7) \\
11(5.9) \\
10(5.4)\end{array}$ & $\begin{array}{c}130(93.5) \\
3(2.2) \\
6(4.3)\end{array}$ & $\begin{array}{c}24(77.4) \\
6(19.4) \\
1(3.2)\end{array}$ & $\begin{array}{c}10(66.7) \\
2(13.3) \\
3(20)\end{array}$ & $<0.001$ \\
\hline $\begin{array}{l}\text { Feeding } \\
\text { Independent } \\
\text { With help } \\
\text { Dependent }\end{array}$ & $\begin{array}{l}161(87) \\
18(9.8) \\
6(3.2)\end{array}$ & $\begin{array}{c}127(91.3) \\
9(6.5) \\
3(2.2)\end{array}$ & $\begin{array}{c}24(77.4) \\
6(19.4) \\
1(3.2)\end{array}$ & $\begin{array}{c}10(66.7) \\
3(20) \\
2(13.3)\end{array}$ & 0.013 \\
\hline $\begin{array}{l}\text { Dressing } \\
\text { Independent } \\
\text { With help } \\
\text { Dependent } \\
\end{array}$ & $\begin{array}{c}162(87.6) \\
13(7) \\
10(5.4)\end{array}$ & $\begin{array}{c}128(92.1) \\
5(3.6) \\
6(4.3)\end{array}$ & $\begin{array}{c}24(77.4) \\
6(19.4) \\
1(3.2) \\
\end{array}$ & $\begin{array}{c}10(66.7) \\
2(13.3) \\
3(20)\end{array}$ & 0.001 \\
\hline $\begin{array}{l}\text { Toileting } \\
\text { Independent } \\
\text { With help } \\
\text { Dependent }\end{array}$ & $\begin{array}{c}161(87.6) \\
14(7) \\
10(5.4)\end{array}$ & $\begin{array}{c}127(91.4) \\
6(4.3) \\
6(4.3)\end{array}$ & $\begin{array}{c}25(80.7) \\
5(16.1) \\
1(3.2)\end{array}$ & $\begin{array}{l}9(60) \\
3(20) \\
3(20)\end{array}$ & 0.003 \\
\hline $\begin{array}{l}\text { Attend phone call } \\
\text { Independent } \\
\text { With help } \\
\text { Dependent }\end{array}$ & $\begin{array}{c}108(58.7) \\
53(28.6) \\
24(13)\end{array}$ & $\begin{array}{c}96(69.1) \\
34(24.5) \\
9(6.5)\end{array}$ & $\begin{array}{c}10(32.3) \\
14(45.2) \\
7(22.6)\end{array}$ & $\begin{array}{l}2(13.3) \\
5(33.3) \\
8(53.4)\end{array}$ & $<0.001$ \\
\hline $\begin{array}{l}\text { Driving } \\
\text { Independent } \\
\text { With help } \\
\text { Dependent }\end{array}$ & $\begin{array}{l}121(65.4) \\
45(24.3) \\
19(10.3)\end{array}$ & $\begin{array}{c}106(76.3) \\
24(17.3) \\
9(6.5)\end{array}$ & $\begin{array}{c}11(35.5) \\
16(51.6) \\
4(12.9)\end{array}$ & $\begin{array}{c}4(26.7) \\
5(33.3) \\
6(40)\end{array}$ & $<0.001$ \\
\hline $\begin{array}{l}\text { Cooking } \\
\text { Independent } \\
\text { With help } \\
\text { Dependent }\end{array}$ & $\begin{array}{l}103(55.7) \\
56(30.3) \\
26(14.1)\end{array}$ & $\begin{array}{c}88(63.3) \\
40(28.8) \\
11(7.9)\end{array}$ & $\begin{array}{c}12(38.7) \\
13(41.9) \\
6(19.4)\end{array}$ & $\begin{array}{l}3(20) \\
3(20) \\
9(60)\end{array}$ & $<0.001$ \\
\hline $\begin{array}{l}\text { House keeping } \\
\text { Independent } \\
\text { With help } \\
\text { Dependent }\end{array}$ & $\begin{array}{l}95(51.4) \\
68(36.8) \\
22(11.9)\end{array}$ & $\begin{array}{c}82(59) \\
46(33.1) \\
11(7.9)\end{array}$ & $\begin{array}{l}10(32.3) \\
16(51.6) \\
5(16.1)\end{array}$ & $\begin{array}{l}3(20) \\
6(40) \\
6(40)\end{array}$ & $<0.001$ \\
\hline $\begin{array}{l}\text { Grocery } \\
\text { Independent } \\
\text { With help } \\
\text { Dependent } \\
\end{array}$ & $\begin{array}{l}113(61.1) \\
53(28.6) \\
19(10.3)\end{array}$ & $\begin{array}{c}98(70.5) \\
32(23) \\
9(6.5)\end{array}$ & $\begin{array}{c}12(38.7) \\
15(48.4) \\
4(12.9)\end{array}$ & $\begin{array}{l}3(20) \\
6(40) \\
6(40)\end{array}$ & $<0.001$ \\
\hline $\begin{array}{l}\text { Laundry } \\
\text { Independent } \\
\text { With help } \\
\text { Dependent }\end{array}$ & $\begin{array}{c}98(53) \\
60(32.4) \\
27(14.6)\end{array}$ & $\begin{array}{c}85(61.2) \\
42(30.2) \\
12(8.6)\end{array}$ & $\begin{array}{c}10(32.3) \\
15(48.4) \\
6(19.4)\end{array}$ & $\begin{array}{l}3(20) \\
3(20) \\
9(60)\end{array}$ & $<0.001$ \\
\hline $\begin{array}{l}\text { Self-medication } \\
\text { Independent } \\
\text { With help } \\
\text { Dependent }\end{array}$ & $\begin{array}{c}122(65.9) \\
49(26.5) \\
14(7.6)\end{array}$ & $\begin{array}{c}101(72.7) \\
32(23) \\
6(4.3)\end{array}$ & $\begin{array}{c}15(48.4) \\
13(41.9) \\
3(9.7)\end{array}$ & $\begin{array}{c}6(40) \\
4(26.7) \\
5(33.3) \\
\end{array}$ & $<0.001$ \\
\hline
\end{tabular}


cations/active ageing/en/ Last accessed: Jan 2018.

2. United States Bureau of Census. International data base; 2017. Available from: https://www.census.gov/datatools/demo/idb/informationGateway.ph p Last accessed: Aug 2017.

3. Health statistics and health information systems. World Health Organisation. Proposed working definition of an older person in Africa for the MDS Project. Available from: http://www.who.int/ healthinfo/survey/ageingdefnolder/en/ Last accessed: Dec 2017.

4. Ganguly SS, Al-Lawati A, Al-Shafaee MA, Duttagupta KK. Epidemiological transition of some diseases in Oman: a situational analysis. World Hosp Health Serv 2009;45:26-31.

5. Wahdan MH. The epidemiological transition. Eastern Med Health $\mathrm{J}=\mathrm{Rev}$ Sante Med Orient $=$ al-Majallah al-sihhiyah lisharq al-mutawassit 1996;2:8-20.

6. Al-Lamki L. Acute coronary syndrome, diabetes and hypertension: Oman must pay more attention to chronic non-communicable diseases. Sultan Qaboos Univ Med J 2011;11:318-21.

7. Ellis G, Whitehead MA, Robinson D, et al. Comprehensive geriatric assessment for older adults admitted to hospital: meta-analysis of randomised controlled trials. BMJ 2011;343.

8. Ganatra HA, Zafar SN, Qidwai W, Rozi S. Prevalence and predictors of depression among an elderly population of Pakistan. Aging Ment Health 2008;12: 349-56.

9. Bhurgri H, Gowani SA, Itrat A, et al. Awareness of cancer risk factors among patients and attendants presenting to a tertiary care hospital in Karachi, Pakistan. J Pak Med Assoc 2008;58: 584-8.

10. Itrat A, Taqui AM, Qazi F, Qidwai W. Family systems: perceptions of elderly patients and their attendents presenting at a university hospital in Karachi, Pakistan. J Pak Med Assoc 2007;57: 106-10.

11. Taqui AM, Itrat A, Qidwai W, Qadri Z. Depression in the elderly: Does family system play a role? A cross-sectional study. BMC Psychiatry 2007;7:57.

12. Directorate general of primary healthcare, Ministry of Health, Oman; 2015. Available from: https://www.moh.gov. om/documents/272928/0/Progress+Rep ort+DGPHC/d3eea 102-63d5-48fb8404-2ff3514b0df0 Last accessed: June 2017.

13. The Seventh Report of the Joint National Committee on Prevention, Detection, Evaluation, and Treatment of High
Blood Pressure. National High Blood Pressure Education Program.National Institutes of Health National Heart, Lung, and Blood Institute; 2003. Available from: https://www.nhlbi.nih. gov/files/docs/guidelines/express.pdf Last accessed: Sep 2017.

14. Al Shaali A, Al Jaziri A. Health profile of elderly patients registered in the elderly home based primary care Dubai, UAE. Middle East J Age Aging 2015; 12:13-9.

15. Al-Nozha MM, Abdullah M, Arafah MR, et al. Hypertension in Saudi Arabia. Saudi Med J 2007;28:77-84.

16. Khamis S. A study of morbidity pattern among geriatric population in Fayoum governorate, Egypt. J Am Sci 2015;11.

17. Primatesta P, Brookes M, Poulter NR. Improved hypertension management and control: results from the health survey for England 1998. Hypertension 2001;38:827-32.

18. Wu D, Mansoor G, Kempf C. Clinical attributes, treatment, and control in hypertension $(\mathrm{CATCH})$ - a French and Italian longitudinal patient database study. Clin Hyperten 2015;21:18.

19. Mwangi J, Kulane A, Van Hoi L. Chronic diseases among the elderly in a rural Vietnam: prevalence, associated socio-demographic factors and healthcare expenditures. Int $\mathbf{J}$ Equity Health 2015; $14: 134$.

20. Park JM. Health status and health services utilization in elderly Koreans. Int J Equity Health 2014;13:73.

21. Al-Nozha MM, Al-Maatouq MA, AlMazrou YY, et al. Diabetes mellitus in Saudi Arabia. Saudi Med J 2004;25:1603-10.

22. Kirchberger I, Meisinger C, Heier M, et al. Patterns of multimorbidity in the aged population. Results from the KORA-Age Study. PLoS One 2012;7: e30556.

23. Liu M, Wang J, He Y, et al. Awareness, treatment and control of type 2 diabetes among Chinese elderly and its changing trend for past decade. BMC Public Health 2016;16:278.

24. Ylli A. Health and social conditions of older people in Albania": baseline data from a National Survey. Public Health Rev 2010;32:549-60.

25. Danaei G, Finucane MM, Lu Y, et al. National, regional, and global trends in fasting plasma glucose and diabetes prevalence since 1980: systematic analysis of health examination surveys and epidemiological studies with 370 country-years and 2.7 million participants. Lancet 2011;378:31-40.

26. Porapakkham Y, Pattaraarchachai J,
Aekplakorn W. Prevalence, awareness, treatment and control of hypertension and diabetes mellitus among the elderly: the 2004 National Health Examination Survey III, Thailand. Singapore Med J 2008;49:868-73.

27. Verschuren WM, Jacobs DR, Bloemberg BP, et al. Serum total cholesterol and long-term coronary heart disease mortality in different cultures. Twenty-fiveyear follow-up of the seven countries study. JAMA 1995;274:131-6.

28. Al-Nozha MM, Arafah MR, AlMaatouq MA, et al. Hyperlipidemia in Saudi Arabia. Saudi Med J 2008;29: 282-7.

29. Sazlina SG. Health screening for older people - what are the current recommendations? Malays Fam Phys 2015; 10:2-10.

30. Joshi R, Taksande B, Kalantri SP, et al. Prevalence of cardiovascular risk factors among rural population of elderly in Wardha district. J Cardiovasc Dis Res 2013;4:140-6.

31. Almas K, al-Shammari B, al-Dukhyeel S. Education level, oral hygiene and smoking habits of an elderly Saudi population in Riyadh. Odontostomatol Trop 2003;26:4-6.

32. Boulos C, Salameh P, Barberger-Gateau P. The AMEL study, a cross sectional population-based survey on aging and malnutrition in 1200 elderly Lebanese living in rural settings: protocol and sample characteristics. BMC Public Health 2013;13:573.

33. Khattab A, Javaid A, Iraqi G, et al. Smoking habits in the Middle East and North Africa: results of the BREATHE study. Respir Med 2012;106:S16-24.

34. Liu F, Woodrow J, Loucks-Atkinson A, et al. Smoking and alcohol consumption patterns among elderly Canadians with mobility disabilities. BMC Res Notes 2013;6:218-28.

35. Lugo A, La Vecchia C, Boccia S, et al. Patterns of smoking prevalence among the elderly in Europe. Int J Environ Res Public Health 2013;10:4418-31.

36. Murray CJ, Vos T, Lozano R, et al. Disability-adjusted life years (DALYs) for 291 diseases and injuries in 21 regions, 1990-2010: a systematic analysis for the Global Burden of Disease Study 2010. Lancet 2012;380: 2197-223.

37. Yusuf S, Reddy S, Ounpuu S, Anand S. Global burden of cardiovascular diseases: Part II: variations in cardiovascular disease by specific ethnic groups and geographic regions and prevention strategies. Circulation 2001;104: 2855-64. 
38. Al-Modeer MA, Hassanien NS, Jabloun CM. Profile of morbidity among elderly at home health care service in Southern Saudi Arabia. J Family Community Med 2013;20:53-7.

39. Zeidan RK, Farah R, Chahine MN, et al. Prevalence and correlates of coronary heart disease: first populationbased study in Lebanon. Vasc Health Risk Manage 2016;12:75-84.

40. Green V. The domino effect: obesity, type 2 diabetes and cardiovascular disease. Br J Community Nurs 2005;10: 358-61.
41. Al-Abbad FA, Al-Sowielem S. Prevalence of obesity. Saudi Med J 1998;19:608-13.

42. Khader Y, Batieha A, Ajlouni H, et al. Obesity in Jordan: prevalence, associated factors, comorbidities, and change in prevalence over ten years. Metab Syndr Relat Disord 2008;6:113-20.

43. Al-Sinawi H, Al-Alawi M, Al-Lawati $\mathrm{R}$, et al. Emerging burden of frail young and elderly persons in Oman: For whom the bell tolls? Sultan Qaboos Univ Med J 2012;12:169-76.

44. Al-Mahadi MA, Elzubier AG.
Assessment of the functional status of elderly subjects in Qassim region, Saudi Arabia. J Roy Soc Health 1997;117.

45. Youssef RM. Comprehensive health assessment of senior citizens in $\mathrm{Al}$ Karak governorate, Jordan. East Med Health $\mathrm{J}=$ Rev Sante Med Orient $=$ alMajallah al-sihhiyah li-sharq almutawassit 2005;11:334-8.

46. Mathur N. Assessment of functional capacity in patients attending geriatrics outpatient department at Civil Hospital, Ahmedabad. CHRISMED J Health Res 2016;3:28-32. 